\title{
Sistem Deteksi Lubang pada Pedesterian dengan Teknik Pengolahan Citra
}

\author{
Indrabayu $^{1 *}$, Ahmad Rifaldi ${ }^{1}$, Intan Sari Areni ${ }^{2}$, Ingrid Nurtanio ${ }^{1}$, Anugrayani Bustamin $^{1}$ \\ ${ }^{1}$ Departemen Teknik Informatika, Fakultas Teknik, Universitas Hasanuddin \\ ${ }^{2}$ Departemen Teknik Elektro, Fakultas Teknik, Universitas Hasanuddin \\ Jl. Poros Malino km. 6, Bontomarannu, Kabupaten Gowa, Sulawesi Selatan 92171 \\ *Email: indrabayu@unhas.ac.id
}

DOI: 10.25042/jpe.112019.04

\begin{abstract}
Abstrak
Kawasan pedestrian di Indonesia masih tergolong belum optimal dalam memfasilitasi penggunanya, dalam hal ini para pejalan kaki. Tidak sedikit dari kawasan tersebut masih ditemui jalanan pedestrian yang berlubang, hal ini bisa saja mencelakai pejalan kaki terutama pada penyandang tunanetra. Untuk itu dilakukan penelitian untuk membuat sistem yang dapat mendeteksi dan mengestimasi jarak lubang dengan pengolahan citra menggunakan mono kamera yang dapat membantu penyandang tunanetra. Metode yang digunakan untuk mendeteksi lubang adalah metode Threshold + Blob Analysis dan metode HSV. Hasil yang diperoleh menunjukkan tingkat akurasi pendeteksian lubang dengan menggunakan metode Threshold+Blob Analysis lebih baik dari metode HSV. Tingkat akurasi rata-rata Threshold+Blob Analysis sebesar $88,91 \%$, sedangkan untuk metode HSV sebesar $86,82 \%$.
\end{abstract}

\begin{abstract}
Pothole Detection System on Pedesterian using Image Processing Techniques. The pedestrian areas in Indonesia are still far from optimal in facilitating the users or the pedestrians. Potholed pedestrian areas are found in many parts of the street. This issue can harm pedestrians, especially blind people. For this reason, research has been carried out to create a system that can detect and estimate hole distances by processing images using mono cameras that can help blind people. The methods used to detect holes are the Threshold + Blob Analysis method and the HSV method. The obtained results indicate the level of accuracy of hole detection using the Threshold + Blob Analysis method is better than the HSV method. The average accuracy level of Threshold + Blob Analysis is $88.91 \%$, while for the HSV method is $86.82 \%$.
\end{abstract}

Kata Kunci: Blob analysis, deteksi lubang, HSV, tuna netra

\section{Pendahuluan}

Lubang di jalan merupakan suatu hal yang dihindari, bukan hanya bagi pengendara motor atau mobil, lubang juga dapat mencelakakan pejalan kaki, khususnya pejalan kaki yang memiliki keterbatasan fisik dalam hal ini penyandang tunanetra. Lubang dapat terbentuk karena berbagai hal, salah satu penyebabnya ialah air yang menggenang [1].

Alat bantu tradisional yang biasa digunakan oleh penyandang tuna netra ialah tongkat pemandu dan anjing penuntun, kelemahannya ialah keterampilan dalam penggunaan alat dan diperlukan waktu untuk melatih anjing penuntun tersebut [2].

Berbagai penelitian sebelumnya memberikan solusi dengan membuat sebuah tongkat pintar yang dapat membantu kebutuhan tunanetra dalam mobilitasnya, penelitian yang dilakukan oleh Rao pada tahun 2016 menggunakan laser dan mono kamera dalam membuat sistem yang dapat mendeteksi dan mengenali lubang ataupun retakan pada jalan [3]. Penelitian oleh Shurti Dambhare dan Prof. A. Sakhare menggunakan kamera stereo, proximity sensor, ultrasonic sensor dan modul GPS, dalam menghasilkan sebuah tongkat pintar untuk penyandang tunanetra [2].

Penelitian-penelitian yang telah dilakukan sebelumnya masih fokus pada pendeteksian lubang dan estimasi jarak lubang menggunakan lebih dari satu sensor atau tambahan perangkat lain. Oleh karena itu, pada penelitian ini dibuat sebuah sistem yang hanya menggunakan mono kamera untuk mendeteksi sekaligus menghitung estimasi jarak lubang berdasarkan teknik pengolahan citra. Metode yang digunakan yaitu Thresholding + Blob Analysis yang akan dibandingkan dengan metode HSV. 


\section{Metodologi Penelitian}

Alur penelitian diperlihatkan pada Gambar 1. Data masukan pada penelitian ini adalah data video dengan resolusi 1920 x 1080 dengan format file mp4. Jumlah data masukan sebanyak 12 data video. Data masukan selanjutnya di ekstrak menjadi frame-frame lalu dilakukan preprocessing pada hasil ekstraksi. Untuk mendeteksi lubang digunakan dua metode pengolahan citra, yaitu Thresholding + Blob Analysis dan $H S V$. Unjuk kerja dari kedua metode akan dibandingkan dengan menggunakan software Matlab.

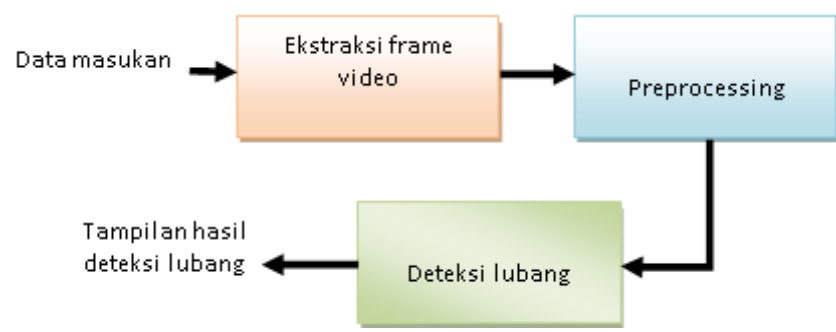

Gambar 1. Alur Penelitian

\subsection{Ekstraksi Frame}

Pada tahap ini, video di ekstraksi menjadi beberapa frame yang akan diolah satu persatu sampai frame terakhir dalam video. Tahapan algoritma untuk ekstraksi frame diawali dengan melakukan inisialisasi terhadap jumlah frame video masukan.

\subsection{Preprocessing}

Pada bagian ini akan dilakukan beberapa tahapan, yaitu:

\section{- Cropping}

Video yang telah di ekstrak menjadi frameframe akan di-crop agar citra yang tidak perlu untuk di proses akan dibuang. Hal yang dibutuhkan dalam melakukan cropping adalah adanya koordinat awal, panjang dan lebar area crop.

- Resize

Pada tahap ini citra di resize ke ukuran $640 \mathrm{x}$ 480 piksel agar proses komputasi bisa lebih cepat.

\subsection{Metode Thresholding}

Metode Thresholding merupakan metode pengolahan citra untuk memetakan piksel yang memenuhi syarat ambang batas dan dipetakan ke nilai piksel yang dikehendaki. Pada penelitian ini digunakan metode thresholding tunggal seperti diperlihatkan pada persamaan (1). Piksel - piksel yang nilai intensitasnya dibawah 30 diubah menjadi hitam (nilai intensitas 0), sedangkan piksel-piksel yang nilai intensitasnya di atas 30 diubah menjadi warna putih (nilai intensitas $=255)$ [4].

$$
f_{0}(x, y)=\left\{\begin{array}{c}
0, f_{1}(x, y)<30 \\
255, f_{1}(x, y) \geq 30
\end{array}\right.
$$

dimana $f_{o}(x, y)$ adalah citra hasil threshold.

Perbandingan hasil dari beberapa threshold diperlihatkan pada Gambar 2. Hasil threshold dengan nilai 30/255 lebih bersih dari noise dibandingkan dengan nilai threshold lainnya.

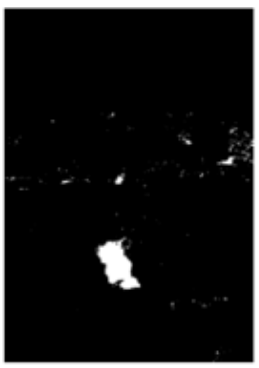

Threshold 30/255

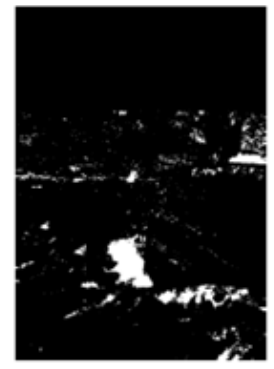

Threshold 50/255

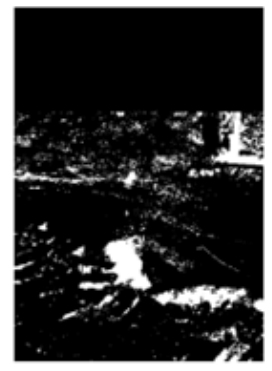

Threshold 70/255
Gambar 2. Hasil perbandingan nilai threshold

\subsection{Blob Analysis}

Pada pengolahan citra yang menggunakan segmentasi foreground, analisis blob merupakan teknik yang digunakan untuk menyatakan luas area piksel dari suatu image yang menjadi fokus deteksi [5]. Berdasarkan fungsi tersebut, pada penelitian ini digunakan metode blob yang nantinya digunakan sebagai filter berdasarkan luas area untuk mengeleminasi objek-objek yang bukan lubang namun terdeteksi sebagai lubang pada sistem. Untuk menentukan nilai blob, ada beberapa hal yang harus diketahui untuk menghasilkan sebuah blob yang optimal. Penentuan luas blob pada setiap objek pada proses segmentasi foreground perlu dianalisis karena nilai blob pada tiap objek akan berbeda. Hal ini dipengaruhi oleh fitur objek seperti ukuran, jenis, dan teknik pengambilan data video [6].

Nilai blob minimal yang digunakan pada penelitian ini sebesar 2000 dan nilai blob maksimalnya sebesar 25000 jadi sebuah objek 
akan dikategorikan sebagai lubang jika luas areanya diantara 2000 dan 25000.

\subsection{Segmentasi Warna dengan HSV}

Segmentasi warna merupakan proses segmentasi dengan pendekatan daerah yang bekerja dengan menganalisis nilai warna dari tiap piksel pada citra dan membagi citra tersebut sesuai fitur yang diinginkan. Segmentasi citra dengan deteksi warna HSV menggunakan dasar seleksi warna pada model warna HSV dengan nilai toleransi tertentu [7].

Pada metode segmentasi dengan deteksi warna HSV dilakukan pemilihan sampel piksel sebagai acuan warna untuk membentuk segmen yang diinginkan [8]. Citra digital menggunakan model warna $R G B$ sebagai acuan warna, oleh karena itu proses awal pada metode ini memerlukan konversi model warna $R G B$ ke $H S V$. Untuk membentuk segmen sesuai dengan warna yang diinginkan maka ditentukan nilai toleransi pada setiap dimensi warna $H S V$, kemudian nilai toleransi tersebut digunakan dalam perhitungan proses adaptive threshold. Hasil dari proses threshold tersebut akan membentuk segmen area dengan warna sesuai toleransi yang diinginkan.

Penelitian ini menggunakan nilai $H S V$ terendah dengan kode $H S V(0,0,0)$ dan nilai $H S V$ tertinggi dengan kode $\operatorname{HSV}(180,255,30)$, jadi objek yang masuk dalam warna $H S V$ tersebut yang akan dikategorikan sebagai lubang.

\section{Hasil}

Hasil deteksi lubang pada frame 15 hingga frame 17 untuk "Data 01" diperlihatkan pada Gambar 3. Lubang mulai terdeteksi ketika memasuki area ROI.

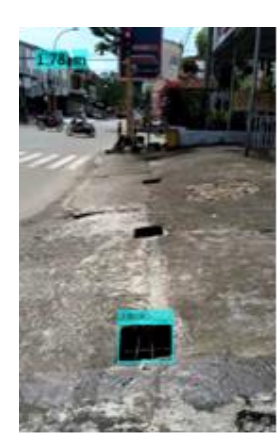

Frame 15

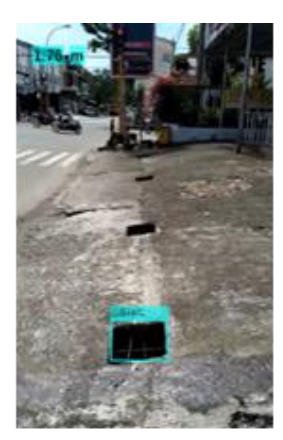

Frame 16

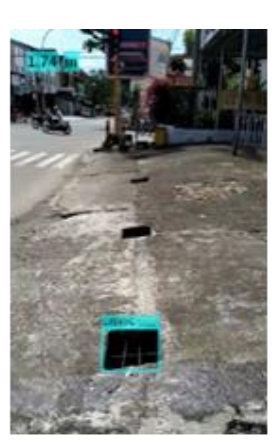

Frame 17
Gambar 3. Hasil deteksi lubang pada "Data 01"
Perbandingan confusion matrix hasil deteksi lubang dengan Thresholding + Blob Analysis dan HSV diperlihatkan pada Tabel 1. Untuk nilai akurasi menentukan Hasil perhitungan akurasi dari kedua metode dengan menggunakan confusion matrix berdasarkan Persamaan (2).

$$
\text { accuracy }=\frac{T P+T N}{T P+T N+F P+F N}
$$

dimana:

1. TP (True Positive), merupakan bounding box pada objek lubang atau dengan kata lain objek tersebut terklasifikasi benar sebagai lubang;

2. FP (False Positive), merupakan bounding box pada objek selain lubang atau dengan kata lain objek tersebut terklasifikasi dengan salah sebagai lubang.

3. FN (False Negative), merupakan objek lubang yang tidak di bounding box atau dengan kata lian objek tersebut terklasifikasi dengan benar sebagai bukan lubang.

4. TN (True Negative), merupakan objek selain lubang yang tidak di bounding box atau dengan kata lian objek tersebut terklasifikasi dengan benar sebagai bukan lubang.

Tabel 1. Perbandingan hasil deteksi lubang dengan metode Thresholding + Blob Analysis dan HSV

\begin{tabular}{|c|c|c|c|c|c|c|c|c|c|}
\hline \multirow{2}{*}{ Data } & \multirow{2}{*}{$\begin{array}{l}\text { Jumlah } \\
\text { frame }\end{array}$} & \multicolumn{4}{|c|}{$\begin{array}{c}\text { Thresholding + Blob } \\
\text { Analysis }\end{array}$} & \multicolumn{4}{|c|}{ HSV } \\
\hline & & $\mathbf{T P}$ & FP & $\mathbf{T N}$ & FN & TP & FP & $\mathbf{T N}$ & FN \\
\hline $\begin{array}{c}\text { Data } \\
01\end{array}$ & 40 & 40 & 0 & 0 & 0 & 40 & 4 & 0 & 0 \\
\hline $\begin{array}{c}\text { Data } \\
02\end{array}$ & 40 & 40 & 0 & 0 & 8 & 37 & 22 & 0 & 3 \\
\hline $\begin{array}{c}\text { Data } \\
03\end{array}$ & 40 & 2 & 38 & 0 & 0 & 47 & 0 & 0 & 19 \\
\hline $\begin{array}{c}\text { Data } \\
04\end{array}$ & 40 & 36 & 4 & 0 & 6 & 43 & 0 & 0 & 6 \\
\hline $\begin{array}{c}\text { Data } \\
05\end{array}$ & 40 & 19 & 11 & 0 & 0 & 40 & 0 & 0 & 0 \\
\hline $\begin{array}{c}\text { Data } \\
06\end{array}$ & 40 & 38 & 2 & 0 & 0 & 40 & 0 & 0 & 0 \\
\hline $\begin{array}{c}\text { Data } \\
07\end{array}$ & 40 & 0 & 0 & 40 & 0 & 38 & 0 & 0 & 1 \\
\hline $\begin{array}{c}\text { Data } \\
08\end{array}$ & 40 & 0 & 0 & 40 & 0 & 0 & 0 & 40 & 0 \\
\hline $\begin{array}{c}\text { Data } \\
09\end{array}$ & 40 & 0 & 0 & 40 & 0 & 0 & 0 & 40 & 0 \\
\hline $\begin{array}{c}\text { Data } \\
10\end{array}$ & 40 & 0 & 0 & 40 & 0 & 0 & 5 & 35 & 0 \\
\hline $\begin{array}{c}\text { Data } \\
11\end{array}$ & 40 & 0 & 0 & 40 & 0 & 0 & 0 & 40 & 0 \\
\hline $\begin{array}{c}\text { Data } \\
12 \\
\end{array}$ & 40 & 0 & 0 & 40 & 0 & 0 & 0 & 40 & 0 \\
\hline Total & 480 & 175 & 55 & 240 & 8 & 285 & 31 & 195 & 29 \\
\hline
\end{tabular}


Setelah melakukan perhitungan terhadap 12 video dengan total frame sebanyak 480, diperoleh nilai akurasi untuk metode Thresholding + Blob Analysis sebesar 88,91\%. Sedangkan untuk metode HSV diperoleh hasil akurasi sebesar 86,82\%. Kesalahan deteksi terjadi akibat adanya objek lain yang berwana gelap masuk ke dalam area deteksi seperti diperlihatkan pada Gambar 4.

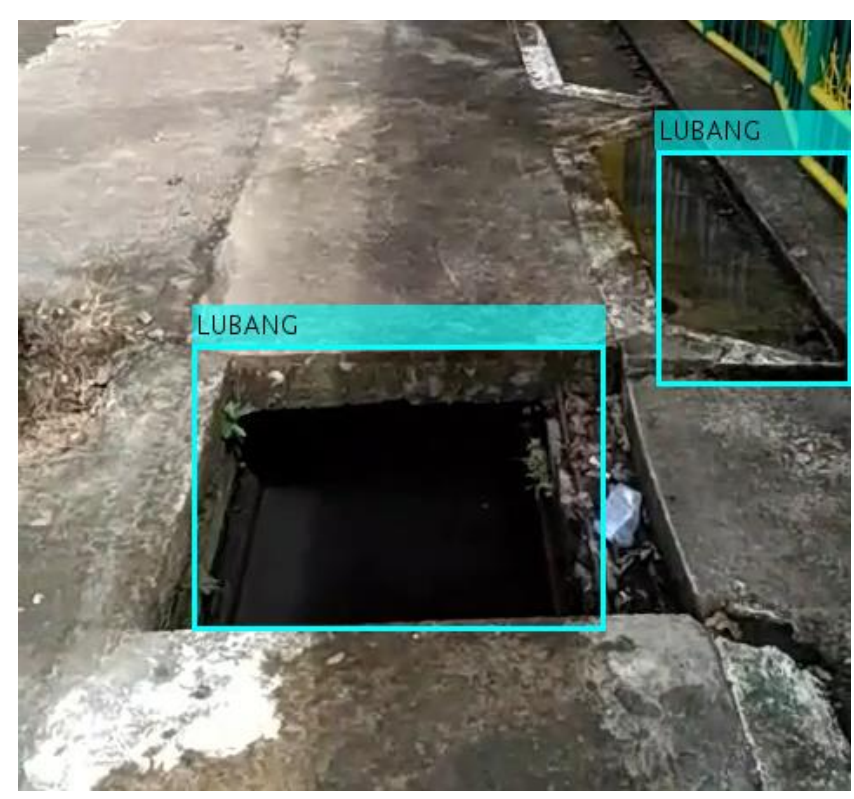

Gambar 4. Contoh kesalahan deteksi lubang

\section{Kesimpulan}

Berdasarkan penelitian yang telah dilakukan, pendeteksian lubang menggunakan metode pengolahan citra telah berhasil dilakukan. Tingkat akurasi dengan metode Threshold + Blob analysis diperoleh sebesar 88,91\% sedangkan tingkat akurasi HSV sebesar 86,82\%. Hasil deteksi memperlihatkan bahwa metode Threshold + Blob Analysis lebih baik dari metode HSV. Penelitian ini akan dikembangkan dengan menghitung estimasi jarak lubang dan pengembangan penggunaan platform Android.

\section{Referensi}

[1] Detik.com. (2016). Detik News. Retrieved 12 12, 2016, from http://news.detik.com/berita-jawatimur/3139479/banyak-lubang-jalan-terbentuk-akibatgenangan-air-hujan.

[2] Shurti Dambhare, P. (2011). Smart Stick for Blind : Obstacle Detection, Artifical vision and Real-time assistance via GPS. II, 3 .

[3] Aravinda S. Rao, J. G. (2016). A Vision-Based System to Detect Pothole and Uneven Surfaces for Assisting Blind People. IEEE ICC 2016, 6.

[4] Rahman, S. (2013, Desember). Lectrurers Blog STTHarapan Medan. Retrieved Juni 22, 2017, from http://sayutirahman.stthmedan.ac.id/2013/12/thresholding.html.

[5] Zakiyabarsi, F., Niswar, M., \& Zainuddin, Z. (2019). Crab Larvae Counter Using Image Processing. EPI International Journal of Engineering, 2(2), 127-131.

[6] Basri (2015). Metode Gaussian Mixture Models Untuk Optimalisasi Perhitungan Kendaraan Dalam Sistem Transportasi Cerdas. Makassar.

[7] Gunanto, S. (2009). Segmentasi warna bagian tubuh manusia pada citra 2D. Proceeding SENTIA.

[8] Giannakopoulos, T. (2008). Matlab color detection software, Department of Informatics and Telecomunications, University of Athens, Greece. Retrieved from htttp://www.di.uoa.gr/ tyiannak. 